\title{
Struktur Retorika Karangan Narasi Mahasiswa Pendidikan Guru Sekolah Dasar STKIP PGRI Lubuklinggau
}

\author{
${ }^{1}$ Sri Murti, ${ }^{2}$ Dian Ramadan Lazuardi \\ Program Studi Pendidikan Bahsaa dan Sastra Indonesia, Jurusan \\ Bahasa dan Seni STKIP PGRI Lubuklinggau \\ Alamat Jl. Mayor Toha Kel. Air Kuti Tlp (0733) 4514322 Lubuklinggau \\ Email: srimurti05@gmail.com
}

\begin{abstract}
Abstrak: Tujuan penelitian ini untuk mendeskripsikan Menggambarkan struktur retorika Karangan Narasi Mahasiswa Pendidikan Guru Sekolah Dasar STKIP PGRI Lubuklinggau, dengan menggunakan metode penelitian kualitatif. Adapun langkah-langkah dalam menganalisis sebagai berikut: a). Analisis data akan dimulai dari analisis "teks" dari teks kumpulan cerpen yang dibaca berulang kali, b). Setelah itu memberikan nomor urut pada kumpulan cerpen tersebut, c). Dilanjutkan dengan memberikan nomor urut juga pada setiap paragraf dalam kumpulan cerpen tersebut, d). Kemudian memberikan kode berdasarkan kategori unsur yang muncul di setiap paragraf (mengidentifikasi unsurunsur teks), e). Membuat lembar deskripsi umum struktur retorika yang muncul tiap paragraf, f).Selanjutnya mendeskripsikan dan membahas hasil analisis data, g). Menarik kesimpulan dari hasil penelitian. Hasil penelitian ini menunjukkan bahwa Secara umum retorika karangan narasi dengan menggunakann teori generic teks labov memiliki pola variatif yaitu 1). 0 yang terdapat pada (KR 8 dan KR 18), 2). 0 - PP terdapat pada (KR 3, KR 4,KR 5,KR 7, KR 13, KR 17,KR 20, KR 22,KR 24, KR 27, R 28, KR 29, KR, 32,dan KR 34), 3). 0 - PP - R terdapat pada ( KR 1, KR 2,KR 6,KR 9,KR 10, KR 11,KR 12,KR 14, KR 16,KR 19, KR 21,KR 23, KR 25 dan KR 26,dan 4). 0 - PP - R - K terdapat pada (KR 15,KR 30 dan KR 31). Selain itu dari 33 karangan narasi tersebut terdiri atas 33 karangan yang memiliki unsur orientasi (0), karangan yang memiliki unsur perumitan peristiwa (PP) berjumlah 29 karangan, sementara unsur resolusi (R) berjumlah 17 karangan, dan terakhir unsur koda (K) berjumlah 3 karangan. Berikut penjelasan masing-masing struktur yang terdapat dalam karangan narasi.
\end{abstract}

\section{Kata Kunci : Struktur Retorika, Karangan dan Narasi}

Abstract: The research aims was to describe the structure of a Narrative Essay rhetoric Describing Student primary school teacher education STKIP PGRI Lubuklinggau, using qualitative research methods. As for the steps in analyzing the following: a). data analysis will be started from an analysis of the "text" of the text of a collection of short stories which is read repeatedly, b). After that number sort on a collection of short stories, followed by c). give the numbers sort as well on each of the paragraphs in the short story collection, d). Then give the code based on the categories of items that appear in each paragraph (identify text elements), e). Make a general description of the sheet structure of rhetoric that appeared every paragraph, $f$ ). Further describes and discusses the results of data analysis, $g$ ). 
Draw conclusions from the results of research. The results of this study show that in general the rhetoric of narrative essay with using theory of generic text labov has a pattern variable that is 1). $O$ contained on the (KR 8 dan KR 18), 2). $O$ - PP contained on the (KR 3, KR 4,KR 5,KR 7, KR 13, KR 17,KR 20, KR 22,KR 24, KR 27, R 28, KR 29, KR, 32,dan KR 34), 3). $O$ - PP $R$ contained on the ( $K R 1, K R 2, K R$ 6,KR 9,KR 10, KR 11,KR 12,KR 14, KR 16,KR 19, KR 21,KR 23, KR 25 dan KR 26,dan 4). $O$ - PP - $R$ - K contained on the (KR 15,KR 30 dan KR 31). Beside it from 33 describing These consist of 33 bouquet that has elements of orientation $(O)$, the describing has elements of perumitan events (PP) totaled 29 describing while elements of the resolution $(R)$ totaled 17 describing, and last element of koda $(K)$ amounted to 3 wreaths. Here's an explanation of each of the structures contained in the narrative essay.

Keyword: Rethoric Structure, Describing, and Narrative

\section{Pendahuluan}

Bahasa sebagai alat yang digunakan oleh manusia untuk proses komunikasi dengan orang lain. Begitu juga dengan pendapat Achmad \& Abdullah, A (2009:3), "Bahasa adalah sistem lambang bunyi yang arbitrer yang dipergunakan oleh para anggota kelompok sosial untuk bekerja sama, berkomunikasi, dan mengidentifikasi diri." Dengan adanya bahasa itulah manusia dapat saling berinteraksi satu sama lainnya. Interaksi itu sendiri adalah berkomunikasi. Komunikasi dapat dilakukan secara lisan dan tulisan. Komunikasi yang dilakukan secara lisan berarti seseorang itu dapat langsung menyampaikan pesan kepada lawan bicaranya sehingga pesan langsung sampai kepada yang dituju, sedangkan secara tulisan lebih cenderung terstruktur dan teratur karena pesan yang akan disampaikan kepada penerima pesan dan waktunya pun cenderung lebih lama, namun isi pesan dapat dipertanggungjawabkan kepada masyarakat luas (Dalman, 2015:1). Kajian bahasa di sini termasuk ke dalam bagian retorika, khususnya dalam retorika bahasa tulisan.

Selama ini retorika dalam bahasa tulisan belum banyak diakui oleh mayoritas pengguna bahasa. Kebanyakan orang menganggap bahwa retorika hanya mutlak milik bahasa lisan saja, namun kenyataannya tidak. Pada awalnya retorika sampai beberapa abad lamanya berada dalam ranah bahasa lisan. Baru pada saat retorika mengalami zaman kemunduran, lahirlah sebuah konsep retorika modern yang mengubah haluan titik tekannya pada bahasa tulisan tanpa harus membelakangi bahasa lisan.

Retorika merupakan suatu cara penggunaan bahasa untuk memperoleh efek estetis. Ia dapat diperoleh melalui kreativitas 
Sri Murti \& Dian Ramadan Lazuardi: Struktur Retorika Karangan Narasi| 137

pengungkapan bahasa, yaitu bagaimana pengarang menyiasati bahasa sebagai sarana untuk mengungkapkan gagasannya. Pengungkapan bahasa dalam sastra mencerminkan sikap dan perasaan pengarang, namun sekaligus dimaksudkan untuk mempengaruhi sikap dan perasaan pembaca yang tercermin dalam nada. Untuk itu, bentuk pengungkapan bahasa haruslah efektif: mampu mendukung gagasan secara tepat sekaligus mengandung sifat estetis sebagai sebuah karya seni. Retorika, pada dasarnya berkaitan dengan pembicaraan tentang dasar-dasar penyusunan sebuah wacana yang efektif (Nurgiyantoro, 2012:295).

Mengkaji struktur retorika bukanlah hal yang menurut sebagian orang dianggap mudah. Orang harus paham betul tentang materi ini. Struktur retorika ini begitu terbilang sulit untuk diteliti, banyak hal yang dibutuhkan di dalamnya. Orang akan membawa manfaat jika ilmu mereka bertambah banyak.

Karangan narasi merupakan salah satu karangan yang bertujuan untuk menceritakan, sehingga struktur retorika memegang peranan penting dalam proses menulis sebuah karangan narasi. Hal ini dikarenakan unsur-unsur kebahasaan dan makna yang digunakan oleh pengarang di dalam mengungkapkan ide dan gagasannya secara jelas dan bernilai seni (Kurniawan, 2013:12). Sejauh ini, analisis struktur retorika prosa belum mendapat perhatian dari peneliti retorika, peneliti yang tercatat pun sedikit yang membahas tentang retorika ini. Berdasarkan hal tersebut akan menambah ketertarikan untuk memahami tentang struktur retorika, sebagai bentuk pembelajaran dan ilmu yang dapat menambah wawasan, hal ini tentu akan menambah rasa peduli kita terhadap analisis retorika itu sendiri.

Analisis struktur retorika dalam karangan narasi ini menggunakan analisis teks labov yang terdiri dari abstrak, orientasi, perumitan peristiwa, resolusi, dan koda yang ada di dalam kumpulan cerpen tersebut. Analisis ini akan mengkaji diantara setiap paragraf di dalam teks cerpen tersebut. Kutipan demi kutipan dianalisis sehingga tentu akan dapat mengetahui struktur retorika yang terdapat di dalamnya.

Berdasarkan uraian di atas peneliti tertarik untuk mengadakan penelitian dengan judul "Struktur Retorika Karangan Narasi Mahasiswa Pendidikan Guru Sekolah Dasar STKIP PGRI Lubuklinggau". Menurut Roberts (dalam Marta, 2014:3) yang menerjemahkan buku retorika 
Aristoteles bahwa Retorika adalah seni mengafeksi (menarik minat) pihak lain dengan tutur dengan cara mengatur unsur-unsur tutur begitu rupa untuk meraih respon pendengar, mengajarkan kaidah dasar pemakaian bahasa yang efektif yang dapat mempersuasi dan dapat memberi informasi yang rasional kepada pihak lain, serta sebagai upaya pemilihan bentuk pengungkapan yang efektif dengan cara lain yang mampu memukau.

Retorika menurut Campbell (dalam Rahmat, 2012:12) yakni upaya yang dilakukan di dalam mencerahkan pemahaman, menyenangkan imajinasi, perasaan, dan kemauan. Ada juga yang memberikan pengertian retorika sebagai seni penggunaan bahasa yang efektif. Dan yang lain mengatakan juga retorika sebagai public speaking atau berbicara di depan umum. Retorika merupakan suatu cara penggunaan bahasa untuk memperoleh efek estetis. Ia dapat diperoleh melalui kreativitas pengungkapan bahasa, yaitu bagaimana pengarang menyiasati bahasa sebagai sarana untuk mengungkapkan gagasannya. Pengungkapan bahasa dalam sastra mencerminkan sikap dan perasaan pengarang, namun sekaligus dimaksudkan untuk mempengaruhi sikap dan perasaan pembaca yang tercermin dalam nada. Untuk itu, bentuk pengungkapan bahasa haruslah efektif: mampu mendukung gagasan secara tepat sekaligus mengandung sifat estetis sebagai sebuah karya seni.

Struktur generik teks narasi di dalam retorika yang dikembangkan oleh Labov \& Trianto (dalam Safnil, 2010:14) adalah abstrak, orientasi, kompleksitas/perumitan peristiwa, resolusi, dan koda. Trianto (dalam Safnil, 2010:14-15) lebih lanjut mengatakan bahwa Abstrak adalah pernyataan singkat mengenai cerita. Pada dasarnya penamaan abstrak di sini dimaksudkan adalah pernyataan atau kesimpulan umum keseluruhan teks. Abstrak biasanya terdapat dibagian awal sebelum memasuki bagian pendahuluan. Untuk membangun sebuah abstrak seorang pembicara tentu memiliki ciri khas yang berbeda. Berdasarkan pengertian tersebut, abstrak merupakan pernyataan singkat mengenai suatu cerita yang di dalamnya terdapat keseluruhan isi dari teks yang akan diceritakan yang biasanya terdapat dibagian awal sebuah cerita.

Orientasi adalah penetapan waktu, tempat, dan karakter cerita untuk diketahui pembaca atau pendengar. Orientasi sebenarnya adalah bagian pendahuluan atau pengantar pada permasalahan inti. Dengan adanya 
Sri Murti \& Dian Ramadan Lazuardi:

Struktur Retorika Karangan Narasi| 139

orientasi penyampaian masalah akan mudah dipahami. Berdasarkan pengertian tersebut, orientasi merupakan sebuah pengantar kepada permasalahan inti dari cerita di mana adanya penempatan waktu, tempat, dan karakter untuk diketahui pembaca atau pendengarnya.

Kompleksitas/perumitan peristiwa adalah peristiwa utama yang membuat peristiwa yang bersangkutan terjadi. Bagian ini berfungsi mengungkapkan masalah yang terjadi dan menyebabkan keharusan untuk mendapatkan penyelesaian. Berdasarkan pengertian tersebut, Kompleksitas/perumitan peristiwa merupakan sebuah peristiwa utama dalam cerita di mana terdapat berbagai masalah-masalah yang timbul sehingga menyebabkan keharusan untuk segera diselesaikan.

Resolusi adalah bagaimana peristiwa terselesaikan. Selain itu resolusi juga bagian teks yang berisi pemecahan masalah, kesimpulan, saran dan sikap penulis. Bagian ini dapat dikatakan sebagai bagian klimaks dalam teks. Berdasarkan pengertian tersebut, resolusi merupakan bagian dari cerita yang memuat akan pemecahan masalah, kesimpulan, saran, dan sikap penulis terhadap masalah yang ada di dalam cerita sehingga permasalahannya pun dapat terselesaikan. Koda adalah jembatan antara dunia perceritaan dan momen perceritaan. koda juga berfungsi sebagai pengakhiran atau penutup teks. Sebagai bagian penutup, tentu saja koda berisi kalimat-kalimat yang mengakhiri dan mengandung penegasan dari kesimpulan. Berdasarkan pengertian tersebut, koda merupakan bagian penegasan dari kesimpulan yang berisi kalimat-kalimat sebagai tanda pengakhiran dari cerita tersebut.

\section{Metode}

Pendekatan yang digunakan peneliti di dalam penelitian ini adalah pendekatan kualitatif, di mana penelitian ini menganalisis berbagai data yang telah diperoleh. Penelitian ini juga penulis menggunakan penelitian kualitatif dalam penelitian ini. Penelitian kualitatif bertujuan untuk mendesripsikan atau menggambarkan apa yang menjadi masalah, kemudian menganalisis dan menafsirkan data yang ada. Penulisan ini mendeskripsikan atau menggambarkan apa yang menjadi masalah, kemudian menganalisis dan menafsirkan data yang ada.

Adapun langkah-langkah dalam menganalisis sebagai berikut: a). Analisis data akan dimulai dari analisis "teks" dari teks kumpulan cerpen 
yang dibaca berulang kali, b). Setelah itu memberikan nomor urut pada kumpulan cerpen tersebut, c). Dilanjutkan dengan memberikan nomor urut juga pada setiap paragraf dalam kumpulan cerpen tersebut, d). Kemudian memberikan kode berdasarkan kategori unsur yang muncul di setiap paragraf (mengidentifikasi unsur-unsur teks), e). Membuat lembar deskripsi umum struktur retorika yang muncul tiap paragraf, f).Selanjutnya mendeskripsikan dan membahas hasil analisis data, g). Menarik kesimpulan dari hasil penelitian.

\section{Hasil dan Pembahasan}

Labov (dalam Trianto, 2002:14) menjelaskan struktur generik teks terdapat 5 unsur, yakni Abstrak, Orientasi, perumitan peristiwa, resolusi, dan koda. Adapun hasil dari penelitian mengenai struktur retorika dalam karangan narasi mahasiswa pgsd stkip pgri lubuklinggau tergambar dalam tabel di bawah ini.

Tabel 3.1

Hasil Analisis Struktur Retorika Pada Karangan Narasi Mahasiswa PGSD STKIP PGRI Lubuklinggau

\begin{tabular}{llcl}
\hline NO & \multicolumn{1}{c}{ Struktur Retorika } & Jumlah & Ket \\
\hline 1 & Abstrak & 0 & \\
2. & Orientasi & 33 & \\
3. & Perumitan peristiwa & 29 & \\
4. & Resolusi & 17 & \\
5. & Koda & 3 & \\
6. & Evaluasi & 0 & \\
\hline
\end{tabular}

Dari hasil analisis data terlihat bahwa dari 33 karangan narasi mahasiswa PGSD STKIP PGRI Lubuklinggau terlihat bahwa tidak semua struktur teks labov dipenuhi oleh semua karangan narasi. Dari enam struktur retorika berdasarkan teks labov yaitu Abstrak (A), Orientasi (O), Perumitan Peristiwa (PP), Resolusi (R), Koda (K), dan Evaluasi (E) hanya empat struktur yag ada dalam karangan narasi. Empat struktur tersebut 
Sri Murti \& Dian Ramadan Lazuardi: Struktur Retorika Karangan Narasi| 141

antara lain Orientasi (O), Perumitan Peristiwa (PP), Resolusi (R),dan Koda (K).

Secara umum retorika karangan narasi dengan menggunakann teori generic teks labov memiliki pola variatif yaitu 1). 0 ngan terdapat pada (KR 8 dan KR 18), 2). 0 - PP terdapat pada (KR 3, KR 4,KR 5,KR 7, KR 13, KR 17,KR 20, KR 22,KR 24, KR 27, R 28, KR 29, KR, 32,dan KR 34), 3). 0 PP - R terdapat pada ( KR 1, KR 2,KR 6,KR 9,KR 10, KR 11,KR 12,KR 14, KR 16,KR 19, KR 21,KR 23, KR 25 dan KR 26,dan 4). 0 - PP - R - K terdapat pada (KR 15,KR 30 dan KR 31).

Selain itu, dari 33 karangan narasi tersebut terdiri atas 33 karangan yang memiliki unsur orientasi (0), karangan yang memiliki unsur perumitan peristiwa (PP) berjumlah 29 karangan, sementara unsur resolusi (R) berjumlah 17 karangan, dan terakhir unsr koda (K) berjumlah 3 karangan. Berikut penjelasan masing-masing struktur yang terdapat dalam karangan narasi.

\section{Orientasi (0)}

Orientasi merupakan penetapan waktu, tempat, dan karakter cerita. Dalam peneitian ini ditemukan pada 33 karangan yang artinya semua karangan memiliki unsur orientasi dalam setiap cerita. Adapun bentuk dari orientasi dibuktikan dari kutipan berikut.

"Namaku Merlin Novasari,akulahir di Musi Rawas 3 November 1998.Nama ayahku Suhardi dan ibuku bernama Masriani. Aku mempunyai 2 saudara kakakku bernama Jeffy dan adikku bernama Marsya. Aku adalah anak kedua dari tiga bersaudara". (KR 1). "Nama saya Risa Oktena,nama panggilan saya Risa agar lebih singkat lagi panggilsaja Sa ataupun Ris, silahkan pilih sesuka hati kalian, nama popular saya yaitu Risa Arasy...." (KR 11) "Aku tinggal bersama orang tuaku bernama Syafrialis dan ibuku bernama Nurbayanisaku mempunyai saudari ayukku yang pertma bernama Selvi Puspita Sari dan saudariku yang kedua bernama Lia Ayu Lestari dan yang terakhir adalah aku bernama Herman Syahputra" (KR 14). 
Dari beberapa kutipan tersebut terlihat bahwa orientasi yang tergambar dalam setiap karangan berisikan tentang pengenalan diri tokoh utama.

\section{Perumitan Peristiwa (PP)}

PP adalah peristiwa utama yang membuat peristiwa di dalm teks terjadi. Adapun bentuk kutipan yang menjelaskan tentang perumitan peristiwa anatara lain;

"Awal saya masuk pesantren, saya merasa jauh sekali perbedaan di rumah sama pesantren. Kalau di rumah biasanya habis zhuhur saya tidur dan tidak mengerjakan solat, tetapi di pesantren 24 jam penuh dengan kegiatan dan 10 jam untuk istirahat, pada saat jam makan saya ngantri utuk makan karena saya ingin mematuhi peraturan yang ada dipesantren jika saya tidak mematuhinya maka saya akan makan di lapangan".(KR 4)

"Setelah itu saya mengikuti seleksi tes SNMPTN yang diadakan serentak, namun hasilnya kurang maksimal, akhirnya keluargaku memutuskan ku untuk kuliah di linggau saja karena banyak factor yang tidak bisa aku tinggalkan....." (KR 11)

"Tersadar karena terhalang jarak dan waktu dengan ibu saya saat ini, dimana saya sudah beranjak menjadi wanita dewasa. Ketika saya lulus SMA waktu itu, ibu saya berniat untuk menyekolahkan saya di jawa bersama dengan beliau, namun niatan ibu saya itu ada pertentangan dari keluarga ayah saya yakni dari kakek dan nenek saya yang selama ini menghidupi saya hingga detik ini saya bisa duduk di bangku perkuliahan" (KR 15)

Dari beberapa kutipan tersebut terlihat bahwa sebuah perumitan peristiwa terdiri atas sebuah permasalahan yang akan menjadi pokok permasalahan dalam sebuah cerita. Hadirnya pola-pola minimal menggambarkan bahwa pengarang hanya menambahkan sebuah peristiwa yang ebrperan menjadi perumitan peristiwa sehingga terjadilan peristiwa utama. Hal ini sejalan dengan pendapat Trianto (dalam Safnil, 2010:13), tidak semua cerita emioiki bagian lengkap. Umumnya tidak ada unsur abstrak, koda dan evaluasi, sedangkan unsur lainnya haruslah ada agar cerita dapat dikatakan sebuah cerita yang 
Sri Murti \& Dian Ramadan Lazuardi: Struktur Retorika Karangan Narasi| 143

terpahami. Perumitan peristiwa ini berperan sebagai pengantar sebuah cerita terhadap konflik yang menjadi bagian utama sebuah cerita.

\section{Resolusi}

Resolusi menggambarkan tentang bagaimana peristiwa terselesaikan. Selain itu, resolusi juga bagian teks yang berisi pemecahan masalah, kesimpulan, saran dan sikap penulis. Adapun bukti kutipan yang menunjukkan struktur atau bagian dari resolusi antara lain;

"Mungkin hidupku penuh banyak kekurangan tetapi pasti ada kelebihan di setiap detik hidupku, karena kau percaya bahwa manusia terlahir ada kekurangan dan kelebihan masing-masing. Bagiku kekuranganku adalah hal unik untukku, hal unik yang kadang harus dilestarikan namun juga harus aku ubah untuk menjadi lebih baik" (KR 9) "Akhir perjalanan di masa SMA adalah ketika kelas 12. Mendengarnya dulu seperti hal yang menyeramkan saat dimana kau harus benar-benar focus untuk belajar. Saat yang menentukan masa depan aku, namun kekeluargaan bersama teman sekelas terjalin erat, sedah banyak kenangan-kenangan yang tergoreskan di benakku saatnya tiba semakin sulit melepaskan sekolah tercinta" (KR 10)

"Semoga keinginanaku untuk membahagiakan keluargaku bisa tercapai dan dimudhkan dalam segala urusan termasuk pendidikan yang saat ini aku tempuh" (KR 16)

Resolusi dalam sebuah cerita berperan sebagai pengantar cerita yang menjelaskan tentang penyelesaian sebuah konflik. Bagian resolusi menjadi bagian yang wajib ada dalam sebuah certa sehingga membentuk sebuah kesatuan atau struktur yang utuh agar sebuah cerita tidak mnggantung. Namun dalam karangan narasi terdapat beberapa karangan yang tidak menjelaskan tentang resolusi ini, sehingga pada beberapa karangan ceritanya terkesan menggantung tanpa penyelesaian.

\section{Koda (K)}

Struktur yang jarang dijumpai dalam sebuah karangan narasi adalah adanya unsur koda yaitu unsur yang menjadi jembatan antara dunia 
perceritaan dan momen perceritaan. koda juga berfungsi sebagai pengakhiran atau penutup teks. Sebagai bagian penutup, tentu saja koda berisi kalimat-kalimat yang mengakhiri dan mengandung penegasan dari kesimpulan. Adapun beberapa kutipan yang mengandung unsur koda diantaranya;

".....Tidak semua anak yang broken home itu lemah dan tidak mempunyai arahan hidup"(KR 15)

"Inilah kebandelanku yang tidak pernah mendengarkan kata orang tua dan selalu membantah omongan orang tua untuk para temantemanku maka jangan pernah lagi untuk membantah omongan orang tua karena akan mengakibatkan penyesalan diakhirnya" (KR 30)

"...Satu kata-kata yang aku ingat sampai sekarang sekelam apapun jadikan masa lalu sebagai lecutan perbaikan” (KR 31)

Unsur koda sangat sedikit ditemukan pada karangan narasi yang ada hanya ditemukan 3 karangan memiliki unsur koda. Unsur $\mathrm{K}$ ini merupakan unsur pelengkap agar lebih menonjol nilai kindahan dan estetikanya.

Dalam menerapkan struktur retorika menggunakan analisis teks labov mengartikan bahwa setiap unsur cerita akan dibagi menjadi beberapa unsur, yaitu abstrak, orientasi, perumitan peristiwa, resolusi, koda dan evaluasi. Karangan narasi yang menjadi data primer sebagian besar memiliki unsur minimal yang harus ada dalam sebuah cerita, yaitu orientasi, perumitan peristiwa, dan resolusi. Hal ini sejalan dengan pendapat Trianto (dalam Safnil, 2010:13) yang mengatakan bahwa tidak semua cerita memiliki bagian lengkap. Hadirnya pola-pola minimal tersebut mencerminkan bahwa sebuah cerita memiliki minimal alur cerita, konflik atau penyelesaian.

Tidak ditemukannya unsur abstrak dalam karangan narasi dan unsur pelengkap lainnya yaitu evaluasi menjadi sesuatu yang biasa dalam sebuah karangan sejalan dengan pendapat Trianto (dalam Safnil, 2010:13) yang mengatakan bahwa tidak semua cerita memiliki unsur yang lengkap. Umumnya tidak ada unsur abstrak, koda, dan evaluasi, sedangkan unsur lainnya haruslah ada agar cerita dikatakan sebagai sebuah cerita yang terpahami. 
Sri Murti \& Dian Ramadan Lazuardi: Struktur Retorika Karangan Narasi| 145

Sementara untuk bagian orientasi merupakan bagian yang dianggap wajib harus ada dalam sebuah cerita, maka dalam data yang ditemukan semua menggunakan orientasi. Orientasi merupakan bagian yang menjelaskan tentang latar tempat, waktu dan karakter cerita atau lebih tepatnya sebuah orientasi berperan sebagai sebuah pengantar cerita. Hal ini sejalan dnegan pendapat Labov (dalam Safnil 2010:114) yang mengatakan bahwa orientasi meupakan penetapan waktu, tempat, dan karakter cerita.

Bagian perumitan peristiwa merupakan pristiwa utama yang menyebabkan peristiwa terjadi. Penggambaran PP yang terdapat dalam karangan narasi mahasiswa STKIP PGRI Lubuklinggau rata-rata mengusung konflik melalui pendeskripsian peristiwa atau tokoh tanpa mengusung konflik. PP menunjukkan peningkatan keaktifan tokoh melalui tindakan yang bersifat fisik ataupun emosi. Hal ini sejalan dengan pendapat Kurniawan (2013:45) yang menjelaskan bahwa untuk masuk pada bagian perumitan peristiwa pengarang menggunakan sinyal transisi linguistik berupa kalimat yang menunjukkan peningkatan keaktifan tokoh yang meliputi gerak, pemikiran, dan emosional sehingga tergambar jelas arah perumitan peristiwa tersebut ke konflik atau alur utuh dalam cerita.

Resolusi dalam sebuah cerita merupakan wujud dari sebuah penyelesaian maslaah. Menurut Labov (dalam Nurgiantoro, 2007:34) resolusi terjadi masih dalam sebuah cerita. Resolusi muncul karena adaya konflik yang harus memiliki penyelesaian. Namun, dalam penelitian ini terdapat beberapa karangan yang tidak memiliki resolusi sebagai bagian penyelesaian dalam sebuah konflik. Padahal resolusi merupakan bagian wajib yang harus ada dalam sebuah cerita. Hal ini sejalan dengan pendapat Trianto (dalam Safnil, 2010:13) yang mengatakan bahwa tidak semua cerita memiliki unsur yang lengkap. Umumnya tidak ada unsur abstrak, koda, dan evaluasi, sedangkan unsur lainnya haruslah ada agar cerita dikatakan sebagai sebuah cerita yang terpahami.

Resolusi berbentuk sebuah jalan keluar dan muatan-muatan (nilainilai kehidupan) semua bentuk resolusi tersebut bisa dipahami pembaca secara tidak langsung sehingga tujuan pengarang tersampaikan secara tersirat maupun tersurat. 
Koda dalam karangan merupakan bagian akhir cerita yang menggambarkan cara pengarang dalam mengakhiri atau menutup cerita. Koda berfungsi sebagai sarana penyimpulan isi cerita yang dikemas dengan menarik sehingga terkesan jelas nilai keindahan dan estetikanya. Jika dalam resolusi berwujud jalan keluar terhadap sebuah konflik, maka koda simpulan yang berisi penutup dari keseua cerita yang iasanya berbentuk nilai-nilai. Koda biasanya berisikan pesan yang ingin disampaikan pengarang kepada pembaca terhadap isi cerita yang dibuatnya. Meskipun koda hanya tergambar pada 3 karangan artinya mahasiswa tersebut sudah memikirkan untuk penyampaian sebuah pesan dari cerita yang ditulisnya tersebut.

\section{Simpulan}

Adapun simpulan dalam penelitian ini secara umum retorika karangan narasi dengan menggunakann teori generic teks labov memiliki pola variatif yaitu 1). 0 ngan terdapat pada (KR 8 dan KR 18), 2). 0 - PP terdapat pada (KR 3, KR 4,KR 5,KR 7, KR 13, KR 17,KR 20, KR 22,KR 24, KR 27, R 28, KR 29, KR, 32,dan KR 34), 3). 0 - PP - R terdapat pada ( KR 1, KR 2,KR 6,KR 9,KR 10, KR 11,KR 12,KR 14, KR 16,KR 19, KR 21,KR 23, KR 25 dan KR 26,dan 4). 0 - PP - R - K terdapat pada (KR 15,KR 30 dan KR 31). Selain itu dari 33 karangan narasi tersebut terdiri atas 33 karangan yang memiliki unsur orientasi (0), karangan yang memiliki unsur perumitan peristiwa (PP) berjumlah 29 karangan, sementara unsur resolusi (R) berjumlah 17 karangan, dan terakhir unsr koda (K) berjumlah 3 karangan. Berikut penjelasan masing-masing struktur yang terdapat dalam karangan narasi.

\section{Daftar Rujukan}

Kurniawan, R. (2013). Pola Retorika dalam Cerita Rakyat Nusantara Berdasarkan Analisis Generik Teks Labov (Disertasi Doktoral, Universitas Bengkulu, 2013).

Marta, I. N. (2014). Retorika. Yogyakarta: Graha Ilmu.

Noermanzah., Emzir., \& Lustyantie, N. (2017). Ragam Retorika dalam Pidato Kenegaraan Presiden Republik Indonesia Susilo Bambang Yudhoyono dan 
Sri Murti \& Dian Ramadan Lazuardi: Struktur Retorika Karangan Narasi| 147 Joko Widodo pada Bidang Pendidikan, 16 (2), 221-238. DOI: 10.24036/humanus.v16i2.8103

Nurgiyantoro, B. (2010). Teori Pengkajian Fiksi. Yogyakarta: Gajah Mada University Press.

Rakhmat, J. (2002). Retorika Modern (Pendekatan Praktis). Bandung: PT Remaja Rosdakarya.

Ryan, M. (2007). Teori Sastra (sebuah Pengantar Praktis). Yogyakarta: Jalasutra.

Safnil. (2010). Pengantar Analisis Retorika Teks. Bengkulu: FKIP UNIB Press.

Sayuti, S. A. (2000). Berkenalan dengan Prosa Fiksi. Yogyakarta: Gama Media.

Tarigan, H. G. (2008). Berbicara sebagai suatu Keterampilan Berbahasa. Bandung: Angkasa. (2011). Prinsip - Prinsip Dasar Sastra. Bandung: Angkasa.

Titscher, Stefan, dkk. (2009). Metode Analisis Teks dan Wacana. (G. Thomas, dkk, Terjemahan). Yogyakarta: Pustaka Pelajar. 